\title{
Relation between the Traces of Nucleation on the Surface and Grain in the Condition of Continuous Casting of Steel
}

\author{
Hidenori MIZUNO, Hisao ESAKA, Kei SHINOZUKA and Manabu TAMURA \\ Department of Materials Science and Engineering, National Defense Academy, 1-10-20 Hashirimizu, Yokosuka $239-8686$ \\ Japan.
}

(Received on September 3, 2007; accepted on November 2, 2007)

\begin{abstract}
Control of nucleation on the surface of solidified shell is of importance to establish the whole structure of continuously-cast products. In the conventional continuous casting of steel, the nucleation of steel takes place on the molten state of mold flux. Lab-scale dipping tests have been carried out, where the solidification satisfied the above-mentioned condition. Changing the material of chill block and mold flux, the cooling rates of initial solidification have been varied systematically. The detailed observations of the surfaces and cross section of solidified shells have been made.

The grain size was affected by cooling rate and decreased monotonously with increasing cooling rate. Many small protrusions have been found on the surface of the solidified shell. They resembled discs as Biloni et al. named. The density of discs was affected by cooling rate and increased with increasing cooling rate. The effective nucleation ratio was defined as the ratio between the number of grains and that of discs. The effective nucleation ratio obtained was a few percent and indicated small dependence on cooling rate in the range of this study.
\end{abstract}

KEY WORDS: initial solidification; nucleation; dendrite; grain; disc.

\section{Introduction}

Since the structures are continuous from the surface to internal region, the surface quality of continuously cast products is of importance. The surface defects such as longitudinal and transverse cracks can be suppressed by the control of condition in initial solidification or in secondary cooling in continuous casting.

In the case of initial solidification in continuous casting of steel, the position that solidification of steel takes place is the interface between molten steel and molten mold flux. Many researchers have illustrated the schematic drawings of the part of meniscus in the mold ${ }^{1-9)}$ and one example of these drawings is shown in Fig. 1. In this figure, the molten steel is contact with molten mold flux at meniscus. At slightly beneath this position, the solidified shell touches both with molten steel and with molten mold flux. Since the temperature gradient is positive toward the molten steel, the solidification of steel should take place on the interface of molten mold flux.

So many pieces of researches on initial solidification have been performed. ${ }^{10-15)}$ However, there have been no pieces of works on the solidification in contact with molten mold flux. One of the distinguished research works on initial solidification was carried out using $\mathrm{Al}-\mathrm{Cu}$ alloys by Biloni et al. ${ }^{10,11)}$ They observed precisely the surface of the solidified shell and found out round-shape protrusions and named disc. They observed the solidified structure on the cross section of disc and also analyzed solute content near the disc. They concluded that the disc was the trace of the nucleation spot on the surface. Furthermore, they depicted the process of solidification as follows; nucleation took place on the surface and it grew and became a disc. At this period, they thought the molten alloy melt undercooled till the solidus temperature. The reason of this statement was that the solute content of the center region of disc was nearly $C_{0}$ (=initial solute composition). After that, the disc developed into a pre-dendrite, which grew out radically from the disc. Further, it developed into normal dendritic structure. They also found that the edge parts of the chill plate offered the positions for nucleation.

Nishi et al. also carried out the similar piece of work. ${ }^{12,13)}$ They also found discs in $\mathrm{Al}-\mathrm{Cu}$ alloys. They also made metallurgical characterization on discs. They concluded that the disc was a nucleation site and alloy melt did not un-

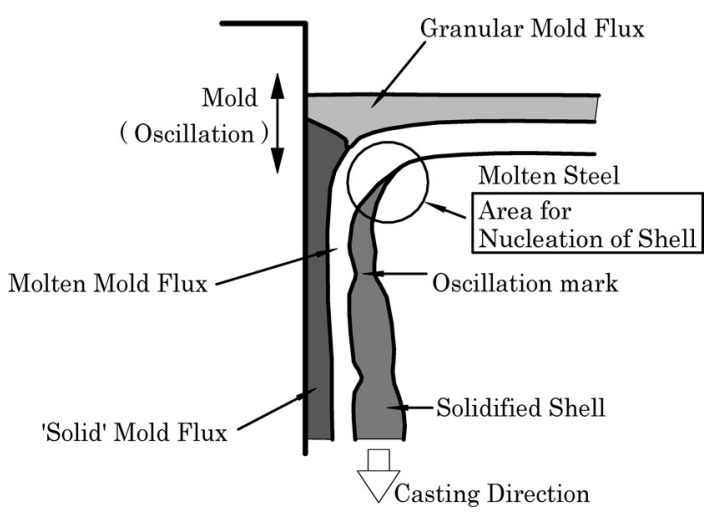

Fig. 1. A schematic drawing of meniscus area in continuous casting of steel. 
Table 1. Chemical composition of molten steel used in this study.

\begin{tabular}{|c|c|c|c|c|c|c|}
\hline $\mathrm{C}$ & $\mathrm{Si}$ & $\mathrm{Mn}$ & $\mathrm{P}$ & $\mathrm{S}$ & $\mathrm{Al}$ & $\mathrm{Fe}$ \\
\hline $0.45 \pm 0.03$ & $0.25 \pm 0.03$ & $0.85 \pm 0.05$ & $0.020 \pm 0.005$ & $0.015 \pm 0.005$ & $0.02 \pm 0.01$ & bal. \\
\hline
\end{tabular}

dercool till solidus temperature. These investigations indicate that the disc may be the trace of nucleation and its formation depends upon condition of solidification.

Recently, Griffiths and Kayikci also discussed about the discs on the surface of $\mathrm{Al}-\mathrm{Cu}$ alloy. ${ }^{16)}$ Judging from the photographs of Biloni et al. and Griffiths and Kayikci, dendritic structure of primary Al phase was also visible. Depending upon the direction of dendrite arms, the grain boundaries were realized. Based upon these observations, sometimes one disc corresponded to one grain. However, there were often some discs in one grain. The latter means that not all discs developed into the grain. In other words, some discs could not operate as the origin of the grain.

By the way, the concept of 'grain' in this study is after Flemings ${ }^{17)}$ and Kurz and Fisher. ${ }^{18)}$ Within a grain, the group of dendrite exhibits the same pattern and the present authors proposed the method for characterization of grain structure near the chill plate. ${ }^{19)}$

In this study, initial solidification of steel on the molten state of mold flux has been investigated in lab-scale experiment. Morphology of the surface of solidified shell and solidified structure on the cross section has been precisely observed in order to understand the solidification of steel on the molten mold flux.

\section{Experimental Procedure}

Using a high frequency induction furnace, $10 \mathrm{~kg}$ of molten steel was prepared in Ar atmosphere. The steel grade used in this study was $\mathrm{S} 45 \mathrm{C}$ and the chemical composition of molten steel is listed in Table 1. The meniscus level of the crucible was protected by zirconia-graphite ring from chemical attack of molten mold flux. Because of prevention of change in chemical composition during experiment, the mold flux was previously decarburized. Then the mold flux was melted and the thickness of molten flux was adjusted to a predetermined value. The chill block, which was made by copper, plain carbon steel (SS400) and SUS304, was dipped at a constant velocity and withdrawn quickly. The size of chill block was $20 \mathrm{~mm}$ thick $\times 60 \mathrm{~mm}$ width $\times 150 \mathrm{~mm}$ length. The velocity and depth of dipping was $1.0 \mathrm{~m} / \mathrm{min}$ and $100 \mathrm{~mm}$, respectively.

The procedure of dipping test is schematically indicated in Fig. 2. Since the mold flux was floating on the molten steel, when the chill block was immersed, mold flux was dragged by the chill block due to viscosity and was placed between the chill block and molten steel. Since the chill block was a large heat sink, the temperature gradient was always positive from the chill block. Therefore, solidification of steel took place on the molten mold flux because of the difference in melting temperature. Finally the solidified shell surrounded the chill block. After withdrawal, the solidified shell was carefully peeled from chill block and characterized. The surface of the shell was observed directly by a FE-SEM. The solidified shell was horizontally cut and mounted in a resin. After polishing by alumina

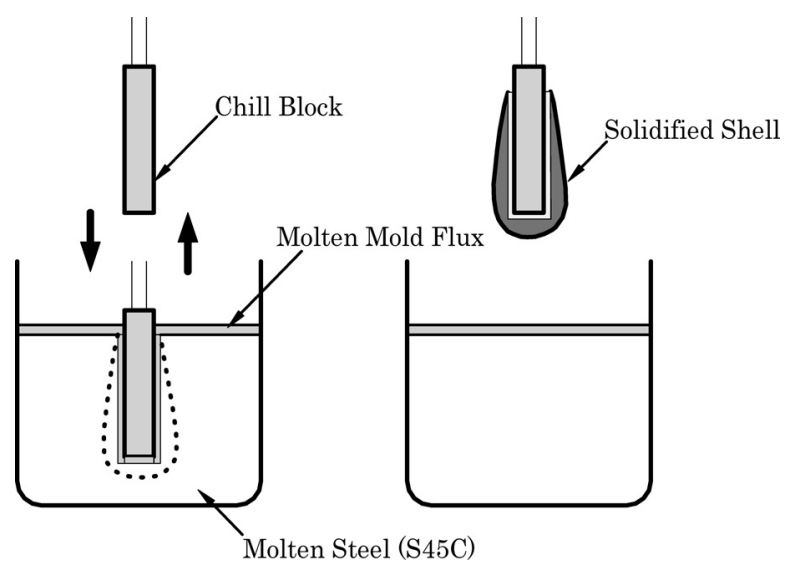

Fig. 2. A schematic view of experimental procedure for dipping test performed in this study.

Table 2. Properties of mold fluxes used in this study.

\begin{tabular}{|l|c|c|c|c|}
\hline & $\begin{array}{c}\text { Melting } \\
\text { Temperature } \\
\left({ }^{\circ} \mathrm{C}\right)\end{array}$ & $\begin{array}{c}\text { Solidification } \\
\text { Temperature } \\
\left({ }^{\circ} \mathrm{C}\right)\end{array}$ & $\begin{array}{c}\text { Viscosity } \\
\text { at } 1350{ }^{\circ} \mathrm{C} \\
(\text { poise })\end{array}$ & $\begin{array}{c}\mathrm{CaO} / \mathrm{SiO}_{2} \\
(-)\end{array}$ \\
\hline Mold flux I & 1140 & $<1000$ & 3.5 & 0.86 \\
\hline Mold flux II & 1140 & 1180 & 1.3 & 1.2 \\
\hline
\end{tabular}

slurry, the specimen was etched by saturated picric acid with surface-active agent. The solidified structure was then observed by an optical microscope.

The two kinds of mold flux were used in this study. The properties of them are summarized in Table 2. They are actually used in continuous casting of steels. The basicity of mold flux I is low and so-called solidification temperature is below $1000^{\circ} \mathrm{C}$. This flux is liable to be glassy during normal cooling in the continuous casting mold. On the other hand, the basicity of mold flux II is larger than unity and solidification temperature is relatively high, $1180^{\circ} \mathrm{C}$. This mold flux has a tendency to crystallize during normal cooling in the mold. The thickness of molten mold flux was set to be $5 \mathrm{~mm}$. In order to analyze the effect of mold flux, the dipping test without mold flux was also performed. Furthermore, in order to examine the effect of thickness of mold flux on solidification, the dipping test with the thickness of mold flux II at $10 \mathrm{~mm}$ was also carried out.

\section{Experimental Result}

\subsection{Observation of Shell}

Figure 3 shows the surface of the solidified shell observed by the FE-SEM. This solidified shell was obtained with a plain carbon steel chill block using mold flux II with thickness at $5 \mathrm{~mm}$. The surface was not flat and unevenness was observed. There were elongated mounds, the size of which was approximately $30 \mu \mathrm{m}$. They might be arms of surface dendrite. Besides these elongated mounds, there are many small protrusions, which are randomly distributed. Figure 4 shows the enlarged view of the protrusion indi- 
cated by arrow in Fig. 3. It is a double ring protrusion and it well resembles the disc that Biloni et al. found in $\mathrm{Al}-\mathrm{Cu}$ alloy. ${ }^{10,11)}$ Close observation was also made for the solidi-

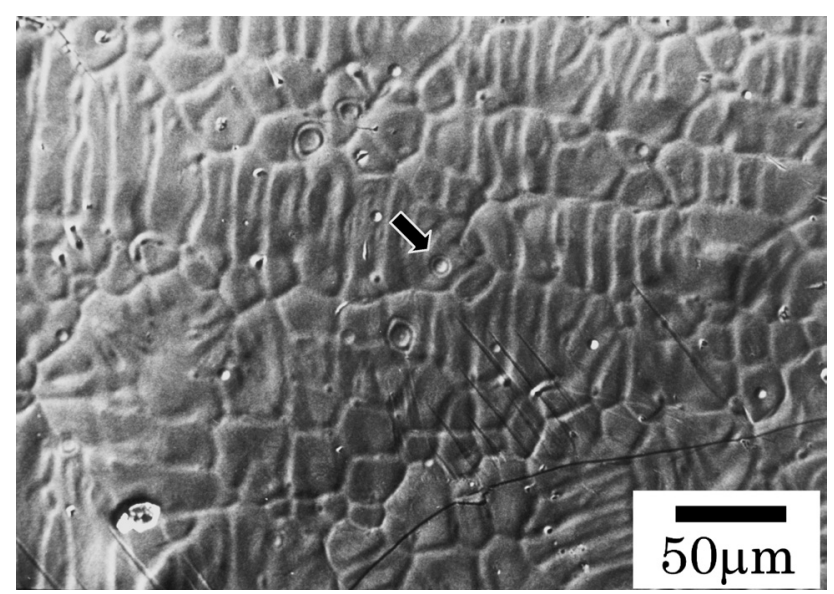

Fig. 3. The surface of the solidified shell observed by a FESEM. Chill block: plain carbon steel, mold flux II with $5 \mathrm{~mm}$.

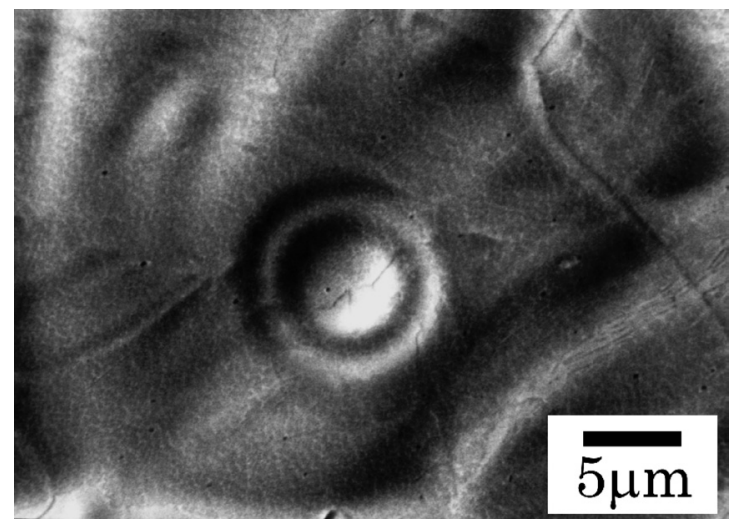

Fig. 4. Enlarged view of disc indicated by a arrow in Fig. 3 . fied shell without mold flux. However, no protrusion was found on the surface of solidified shell without mold flux, independent of the materials of chill block.

\subsection{Solidified Structure Observed on the Cross Sec- tion}

The solidified structures on the horizontal cross section are shown in Fig. 5. Figures 5(a) and 5(b) show the solidified structures that were obtained with plain carbon steel chill block using mold flux I and mold flux II at $5 \mathrm{~mm}$, respectively. Both figures indicate typical dendritic structures. These are also typical initial solidification region of solidified shell and dendrites grow in different directions. However, dendrites, which grow in the same crystallographic direction, exhibit the same pattern. ${ }^{20)}$ Thus, the group of dendrites that exhibit the same pattern is defined as a grain. Figures 6(a) and 6(b) indicate grain boundaries following the definition mentioned above. These grain structures are changing from the chill zone to columnar zone. Therefore the grains are long and narrow along the heat flow direction or growth direction. Here, the grain size or diameter is characterized as a function of distance from surface by the mean lineal intercept. Thus the grain size is corresponding to the width of the narrow grain.

\subsection{Cooling Rate during Solidification Temperature Range}

Since the secondary dendrite arms are clearly observed as indicated in Fig. 5, the cooling rate during solidification temperature range has been estimated using the empirical relationship reported by Suzuki et al. ${ }^{21)}$ Cooling rates at around $450 \mu \mathrm{m}$ from the chill surface are compared with various experimental conditions. The experimental results are summarized in Fig. 7. The cooling rate without mold flux was larger than that with mold flux. The cooling rates with mold flux became small and it is found that the materi-

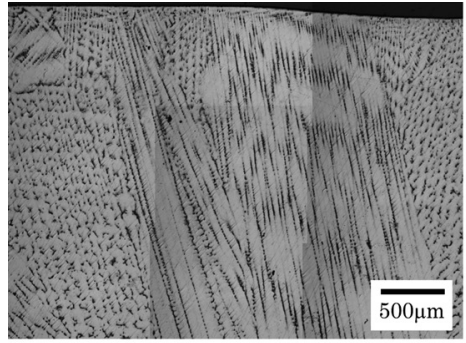

Mold flux I

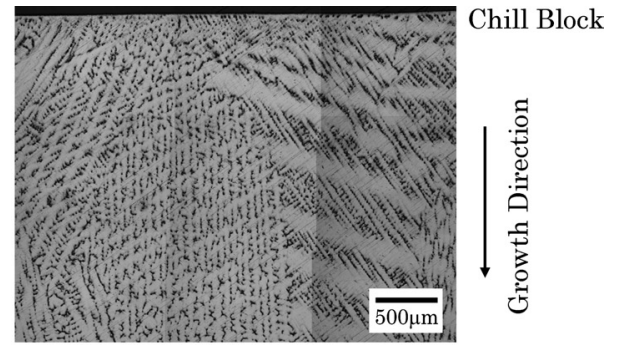

Mold flux II

Fig. 5. Solidified structures of horizontal cross section. Left: chill block: plain carbon steel, mold flux I. Right: chill block: plain carbon steel, mold flux II.

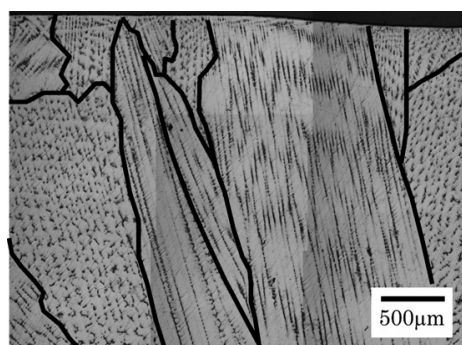

Mold flux I

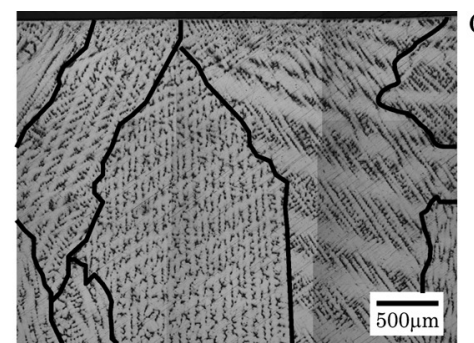

Chill Block

Mold flux II

Fig. 6. Grains of solidified structure shown in Fig. 5. 


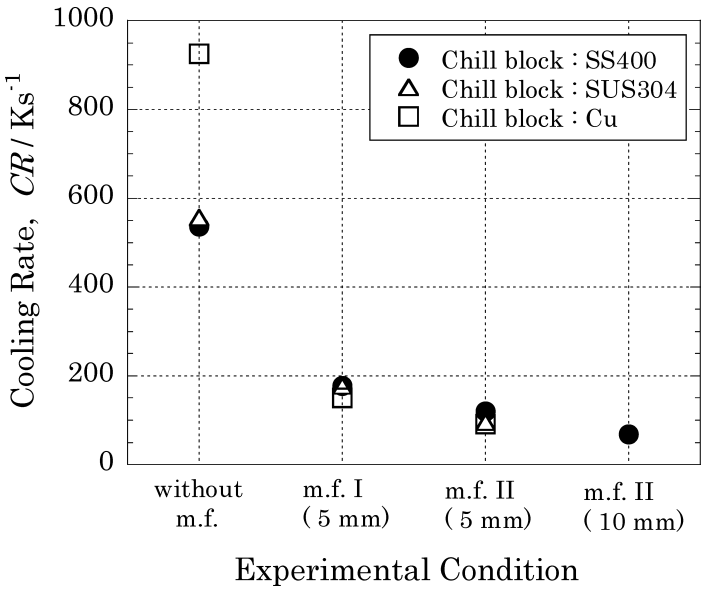

Fig. 7. Relationship between experimental condition and cooling rate determined by the secondary dendrite arm spacing.

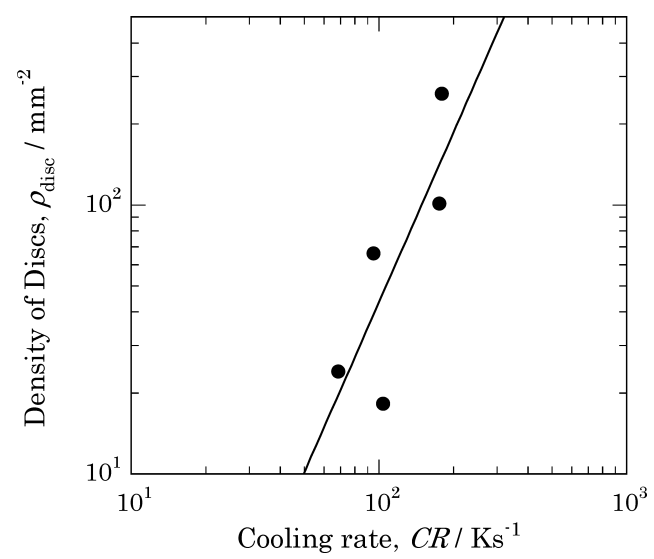

Fig. 8. Relationship between cooling rate and density of discs observed on the surface of the solidified shell.

als of chill block had small effect on cooling rate of solidified shell. The cooling rate with mold flux I was larger than that with mold flux II. The cooling rate was also affected by the thickness of molten mold flux on the molten steel and the mild cooling was achieved with thicker mold flux.

\subsection{Density of Discs}

In order to characterize the disc, the density of disc $\left(\rho_{\text {disc }}\right)$ is defined as the number of discs per unit area of surface. Since the distribution is not uniform, the numbers of discs were measured over $1 \mathrm{~mm}^{2}$. These data were compared with cooling rate measured from secondary dendrite arm spacing and shown in Fig. 8. Though there are some scatters, the density of discs increases with increasing cooling rate. The regression analysis indicates the following functional relationship.

$$
\rho_{\text {disc }} \propto C R^{2.10}
$$

where $C R$ is cooling rate in $\mathrm{K} / \mathrm{s}$.

\subsection{Change of Grain Size in Distance from Surface}

Figure 9 shows the relationship between distance from surface and grain size, which was measured at intervals of $400 \mu \mathrm{m}$. There are 4 levels of the grain size depending upon the solidification condition. As for the relation between grain size and position, the grain size monotonously increases with increasing distance. However, the slopes

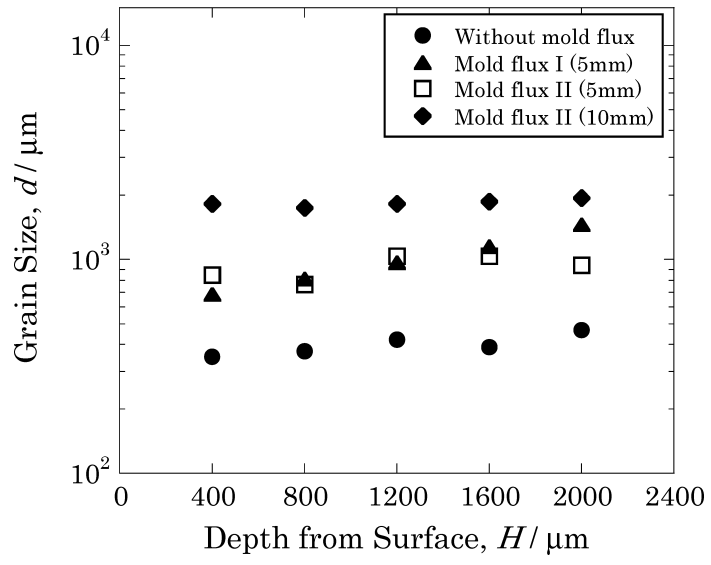

Fig. 9. Change of grain size in distance from the surface.

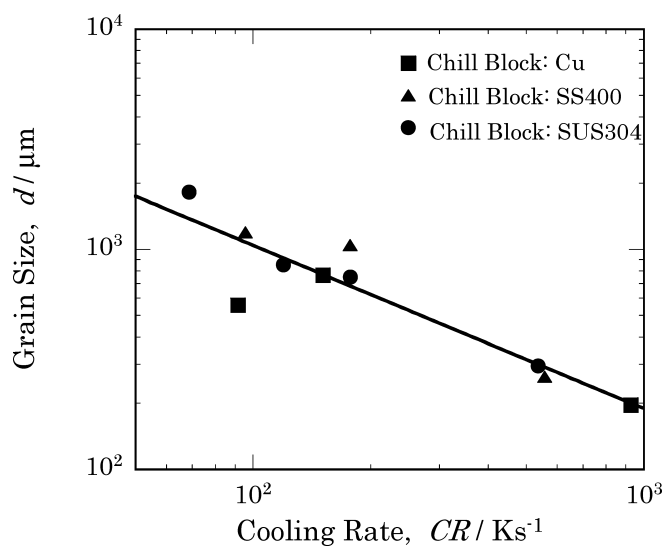

Fig. 10. Relationship between cooling rate and grain size.

with respect to distance are small.

It is difficult to directly measure the grain size at the surface of the shell from the horizontal cross section. Present authors have presented that one can estimate the grain size at the surface with extrapolation of the inner experimental data on grain size. ${ }^{19)}$ However, according to the weak dependence of grain size on distance, it is safely said that the grain size at the chill surface is quite similar to that at $400 \mu \mathrm{m}$ from the chill surface. Therefore, the grain sizes at $400 \mu \mathrm{m}$ from the chill surface have been recognized as those at chill surface.

Figure 10 shows the relationship between cooling rate and the grain size at $400 \mu \mathrm{m}$ from surface. Though there are some scatters in experimental data, the grain size decreases with increasing cooling rate. The regression analysis indicates that the following empirical relationship is satisfied.

$$
d_{\text {grain }} \propto C R^{-0.74}
$$

\subsection{Infiltration of Mold Flux}

The mold flux was always infiltrated between the chill block and solidified shell when the chill block was dipped into molten steel with floating molten mold flux. Relation between thickness of mold flux on the molten steel and that of mold flux infiltrated between the chill block and solidified shell in the selected experiments is shown in Fig. 11. Here, the material of chill block is limited to plain carbon steel. Further, the experimental data on mold flux I at $5 \mathrm{~mm}$ was added for comparison and the values of viscosity at 
$1350^{\circ} \mathrm{C}$ are also indicated. This figure shows that the thickness of infiltration of mold flux increased with increasing the thickness of mold flux on the molten steel. It also increased with increasing the viscosity of mold flux.

\section{Discussion}

\subsection{Cooling Rate}

The cooling rate without mold flux was larger than that with mold flux as shown in Fig. 7. These values depended upon the thermal conductivity of chill block. Thermal conductivities of $\mathrm{Cu}$, plain carbon steel and SUS304 at $0^{\circ} \mathrm{C}$ are 390,65 and $14 \mathrm{~W} / \mathrm{mK}$, respectively. ${ }^{22)}$ Experimental data on the cooling rate were almost in these orders.

The cooling rate with mold flux I was larger than that with mold flux II. Since the chill block just before dipping was nearly room temperature, the molten mold flux on the side to the chill block might immediately become glassy state or crystallize, depending upon the species of mold flux. On the other hand, the molten mold flux on the side to the molten steel remained molten state, independent of the species of mold flux. Consequently, the mold flux was in well contact with the solidified shell. In order to examine the interface between the chill block and mold flux, the surface of mold flux were observed by the FE-SEM. The interface between the chill block and mold flux are shown in Fig. 12. As shown in Fig. 12(a), the surface was very smooth in case of mold flux I. On the contrary, there were many dendritic crystals on the surface in case of mold flux II, as shown in Fig. 12(b). Furthermore, it was found that the interface was not smooth, corresponding to the crystals. The present authors indicated that the mold flux II crystal-

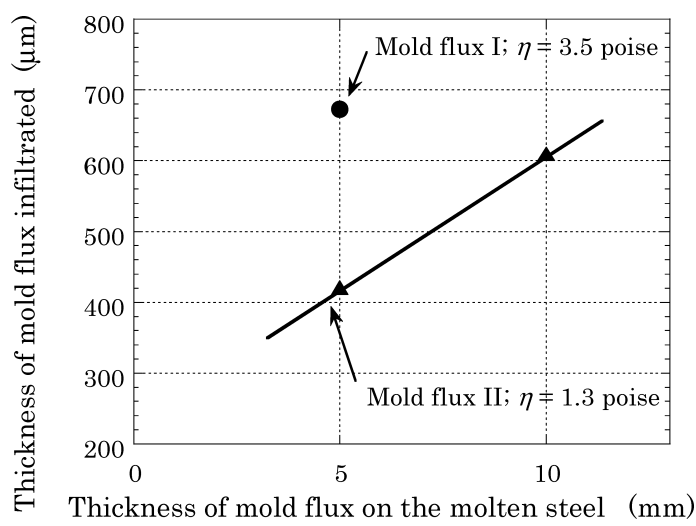

Fig. 11. Thickness of mold flux infiltrated between solidified shell and chill block as a function of thickness of mold flux on the molten steel and viscosity at $1350^{\circ} \mathrm{C}$.

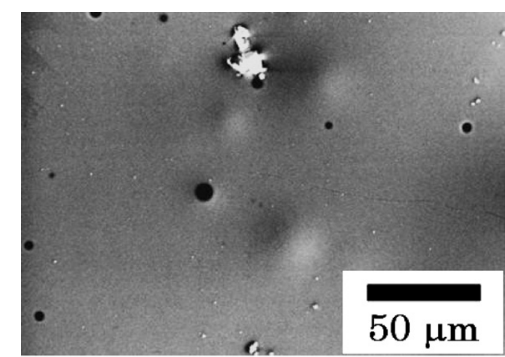

(a) Mold flux I lized quickly over $600^{\circ} \mathrm{C}$ even via glassy state and the surface of mold flux became wavy. ${ }^{23)}$ Thus, there was some air gap between chill block and mold flux. Therefore, the cooling rate during solidification with mold flux II was smaller than that with mold flux I.

As shown in Fig. 7, the mild cooling was achieved with thicker mold flux, because the thermal resistance increased with increasing the thickness of mold flux.

\subsection{Disc}

The diameter of the discs that Biloni et al. investigated in $\mathrm{Al}-\mathrm{Cu}$ alloy was approximately $50 \mu \mathrm{m} .{ }^{10,11)}$ The diameters of the disc obtained in this study were ranging from 2 to $5 \mu \mathrm{m}$. The reason of difference in size is uncertain. However, the appearance is quite similar, therefore, it can be concluded that it is the trace of the position of nucleation on the surface as pointed out by Biloni et al.

In order to analyze the microscopic structure of the disc, an attempt for observation of cross section of the disc was made using the FE-SEM. In order to observe the surface of the solidified shell as well as the cross section, the specimen was tilted approximately $45^{\circ}$. Since the brightness and contrast were different between surface and cross section, two photographs on both side were pasted together. Further, since the work distance was different place to place due to tilting, the magnification was uncertain. The result is shown in Fig. 13. The upper side is the surface and the arrow indicates the disc. Though it is difficult to judge because the sizes of disc and dendrite are too different, it is found that the dendrite arms did not start to grow from the disc in this case. Since the effective nucleation rate obtained in this study is a few percent, which will be discussed in Sec. 4.5, it is plausible that the disc that grew into dendrite was not observed.

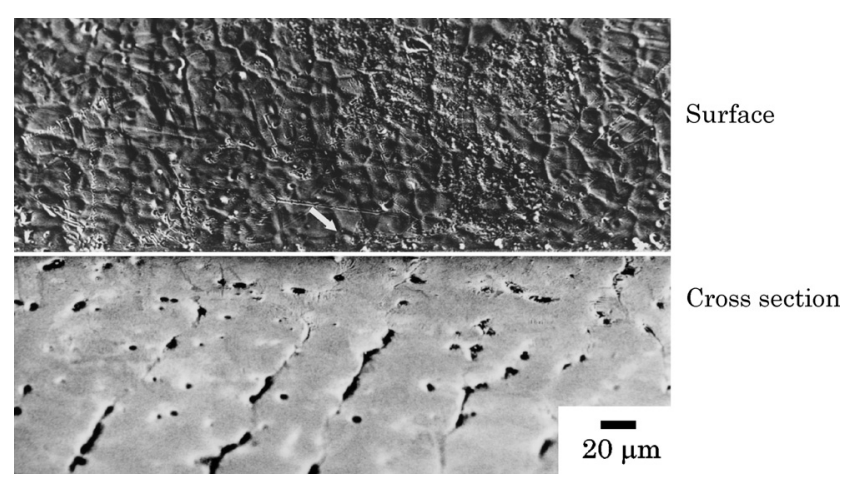

Fig. 13. Observation result of cross section of the disc. The arrow indicates the disc.

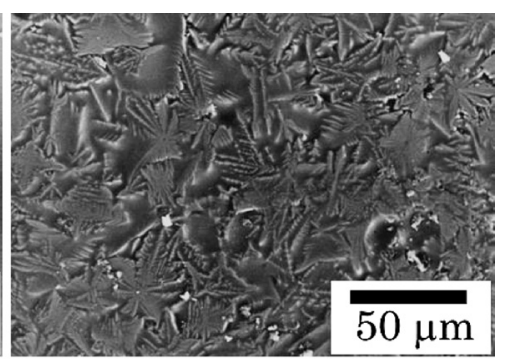

(b) Mold flux II

Fig. 12. Surface of mold flux on the side to the chill block infiltrated between the chill block and solidified shell observed by the FE-SEM. (a) Mold flux I, (b) mold flux II. 
Since the continuously cast products are exposed to air during withdrawal, oxide layer $(=$ scale) forms on the surface. Usually the thickness of scale during continuous casting of steel is thought to be $0.2-0.5 \mathrm{~mm} .^{24)}$ Thus, it is impossible to find out the trace of nucleation on the real continuously cast products. Even the so-called chill zone is also scaled off and the evolution of grain structure is also difficult to characterize using the real continuously-cast slab or bloom. Thanks to the lab-scale experiment and prevention of oxidation, very surface zone of solidified shell could be analyzed for the first time.

No protrusion was found on the shell surface in case of without mold flux. The reason of this is not clear for the moment. One possibility is that the difficulty of nucleation of molten steel may be different, depending upon whether the molten steel touches. When the molten steel touches the molten mold flux, a large undercooling may be necessary for nucleation, because this situation resembles the glass slag method. ${ }^{25}$ ) The other possibility is that the disc becomes too small to be observed by the FE-SEM when the dipping test was performed without mold flux. The size of disc may be influenced by the cooling rate and it may decrease with increasing cooling rate. Therefore, the disc could not be observed in case of without mold flux, because the disc becomes too small. Further investigations on initial solidification of steel are necessary.

The mold flux was always infiltrated between the chill block and solidified shell independent of materials of chill block and mold flux. Recently, Kajitani et al. discussed the mechanism of infiltration of mold flux in continuous casting. ${ }^{26)}$ The mechanism of infiltration for mold flux between mold and solidified shell is not the same as the real continuous casting. However, the initiation of solidification was on the molten mold flux. Therefore, it can be concluded that the condition of initial solidification is the same as the continuous casting of steel.

\subsection{The Dependence of Density of Disc on Cooling Rate}

As shown in Fig. 8 the density of discs increases with increasing cooling rate. Mizukami et al. analyzed the relationship between the cooling rate and undercooling for nucleation in SUS304. They found that the undercooling increased with increasing cooling rate and indicated a following relationship. ${ }^{15)}$

$$
\Delta T \propto C R^{1.0}
$$

Here, their cooling rates ranged from 3000 to $40000 \mathrm{~K} / \mathrm{s}$.

This kind of relation is assumed to be applicable to small cooling range. Therefore, putting the matter indicated in Fig. 8 in another way, the density of discs increases with increasing undercooling for nucleation. Further, Eq. (3) is assumed to be applicable to S45C. Then, substituting Eq. (3) into Eq. (1), the functional relationship between undercooling and the density of disc is obtained as follows.

$$
\rho_{\text {disc }} \propto(\Delta T)^{2.1}
$$

Since $\rho_{\text {disc }}$ is the number of nuclei on the surface, the number of nuclei in a bulk may be calculated. Converting 2D to $3 \mathrm{D}$, the number of nuclei $(N)$ is initial solidification condition as a function of undercooling is obtained as follows.

$$
N \propto(\Delta T)^{2.1 \cdot(3 / 2)}=(\Delta T)^{3.2} .
$$

According to the classical nucleation theory, the nucleation rate depends upon the undercooling for nucleation. ${ }^{27)}$ Until a certain undercooling, the actual nucleation rate can be regarded to be zero and at a certain value, nucleation rate rapidly increases. However, following this concept, the process of solidification in the ingot was not well explained. Rappaz and Gandin therefore, assumed that the nucleation rate was distributed in a Gaussian shape as a function of undercooling $(\Delta T)$ and they found that the solidified structure was well predicted using a cellular automaton method ${ }^{28)}$. Recently, Natsume and Ohsasa proposed that the nucleation rate $(I)$ was expressed by $I \propto(\Delta T)^{n}$ type relation, in order to reduce the number of fitting parameters for numerical modeling of solidified structure. ${ }^{29)}$ They tried to determine the exponent $n$ with Al alloy using unidirectional casting technique. Following their experiment, the exponent $n$ was determined to be between 5.5 and 10.1 .

The number of nuclei is the integration of nucleation rate in a certain period. Thus, $I$ and $N$ can be directly related and they should have the same functional relationship with respect to $\Delta T$. Therefore, the power in Eq. (5) is corresponding to $n$ value in analysis of Natsume and Ohsasa. The power 3.2 in Eq. (5) is smaller than $n$ value obtained by Natsume and Ohsasa, but is larger than unity. This denotes that the number of nuclei increases rapidly with increasing undercooling. Thus, it is safely said that the quite similar functional relationship has been obtained in the density of disc. The exponent $n$ should depend upon alloy system, composition, cleanness of molten metal, heating temperature, cooling rate and so forth. The detailed investigation is necessary for more understanding nucleation phenomena.

\subsection{The Relation between Cooling Rate and Grain Size}

The relation between cooling rate and grain size at $400 \mu \mathrm{m}$ was shown in Fig. 10. As it is shown, the grain size decreases with increasing cooling rate. This result agrees with the result of dropping test made by Kuroda et al. ${ }^{30)}$ This indicates that one can obtain finer grain structure with increasing cooling rate.

Here, the grain is determined as the group of dendrites which grow in the same direction. Therefore, in the grain, the crystallographic orientation is the same. Thus, it is thought that the grain initiated from one crystal. This means that one grain originates from one effective nucleus.

\subsection{Relation between Number of Discs and Grains}

So far, the size of grains has been discussed. In order to discuss the relationship between discs and grains, the experimental data on grain size were transformed to density. Since the density of disc is expressed in $\mathrm{mm}^{-2}$ in this study, the density of grains is also expressed in the same unit. Thus, the density of grains $\left(\rho_{\text {grain }}\right)$, which is the numbers of grains per unit area, is obtained by a following equation, assuming that the grains are packed in a square array.

$$
\rho_{\text {grain }}=\left(\frac{1000}{d}\right)^{2}
$$




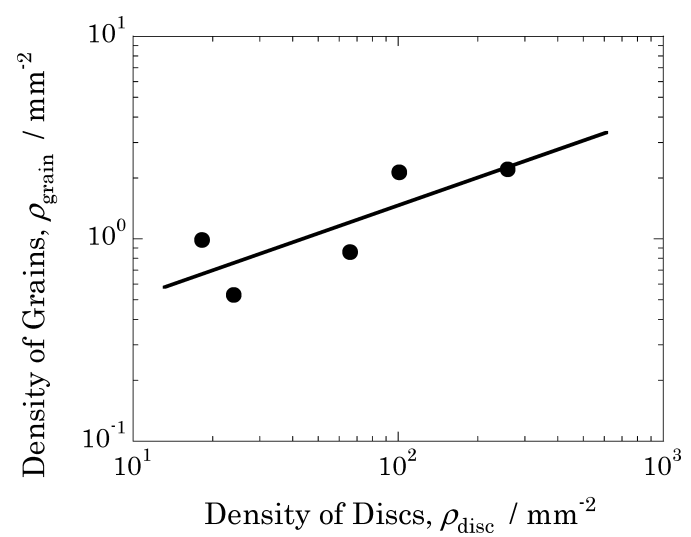

Fig. 14. Relationship between density of discs and density of grains.

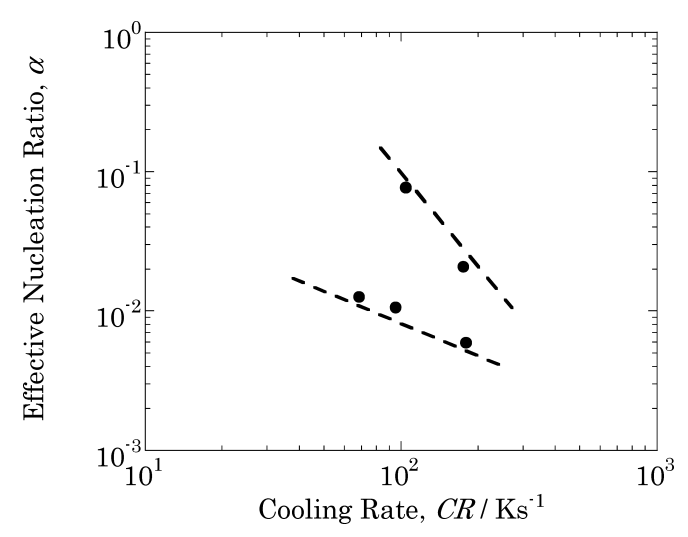

Fig. 15. Relationship between cooling rate and effective nucleation ratio.

where $d$ is the average grain diameter in $\mu \mathrm{m}$.

The relationship between density of discs and that of grains is shown in Fig. 14. It is found that $\rho_{\text {disc }}$ is always larger than $\rho_{\text {grain. }}$. Furthermore, $\rho_{\text {grain }}$ increases with increasing $\rho_{\text {disc }}$.

As mentioned above, the disc is regarded as the trace of the nucleation site on the surface. According to this, the fact that $\rho_{\text {disc }}$ is larger than $\rho_{\text {grain }}$ indicates that not all nuclei develop into grains. The ratio of $\rho_{\text {grain }}$ to $\rho_{\text {disc }}$ is therefore, defined as the effective nucleation ratio $(\alpha)$. The relation between cooling rate and $\alpha$ is shown in Fig. 15. Though there are some scatters, the value of $\alpha$ is small and may decrease with increasing cooling rate in the range of experiment. It is found that the effective nucleation ratio is a few percent. In another words, this signifies that almost all nuclei lost their validity and did not develop into grains. Therefore, it is supposable that the disc that grew into dendrite was not observed because the effective nucleation ratio is small.

\section{Conclusions}

In order to investigate the initiation of initial solidification of steel on the molten mold flux, the dipping tests have been carried out. To change the condition of solidification, the various materials of chill blocks have been used. The detailed observation of the surfaces and the cross section of solidified shells have been made. Following conclusions have been derived.
(1) The grain size was affected by cooling rate and decreased monotonously with increasing cooling rate.

(2) Many small protrusions have been found on the surface of the solidified shell. They resembled 'discs' as Biloni et al. named in their articles.

(3) The density of discs (=number of discs per unit area) was affected by cooling rate and monotonously increased with increasing cooling rate.

(4) The effective nucleation ratio was defined in this study, which was the ratio between the number of grains and that of discs. The effective nucleation ratio obtained was a few percent and slightly decreased with increasing cooling rate in the range of this study.

\section{Acknowledgment}

The authors wish to thank Mr. H. Yamamura, Nippon Steel Corporation, for arrangement of dipping tests and for continuous encouragement.

\section{REFERENCES}

1) T. Emi, H. Nakato, K. Suzuki, Y. Iida and T. Ueda: Tetsu-to-Hagané, 60 (1974), 981.

2) H. Nakato and I. Muchi: Tetsu-to-Hagané, 66 (1980), 33.

3) K. Kawakami, T. Kitagawa, H. Mizukami, H. Uchibori, S. Miyahara, M. Suzuki and Y. Shiratani: Tetsu-to-Hagané, 67 (1981), 1190.

4) H. Nakato, M. Ozawa, K. Kinoshita, Y. Habu and T. Emi: Tetsu-toHagané, 67 (1981), 1200.

5) E. Takeuchi and J. K. Brimacombe: Metall. Trans. B, 15B (1984), 439.

6) R. Taylor and K. C. Mills: Ironmaking Steelmaking, 15 (1988), 187.

7) T. Takawa, T. Takamoto, H. Tomono and K. Tada: Tetsu-to-Hagané, 74 (1988), 2130.

8) K. Schwerdtfeger and H. Sha: Metall. Mater. Trans. B, 31B (2000), 831.

9) Y. Meng and B. G. Thomas: Metall. Trans. B, 34B (2003), 685.

10) H. Biloni and B. Chalmers: Trans. Metall. Soc. AIME, 233 (1965), 373.

11) M. Prates and H. Biloni: Metall. Trans., 3 (1972), 1501.

12) N. Nishi, H. Takeuchi and S. Uchida: Imono, 54 (1982), 718.

13) H. Takeuchi, N. Nishi, S. Takemoto and M. Kawakami: Imono, 56 (1984), 47.

14) T. F. Bower and M. C. Flemings: Trans. Metall. Soc. AIME, 239 (1967), 1620.

15) H. Mizukami, T. Suzuki and T. Umeda: Tetsu-to-Hagané, 78 (1992), 767.

16) W. D. Griffiths and R. Kayikci: J. Mater. Sci., 42 (2007), 4036.

17) M. C. Flemings: Solidification Processing, McGraw-Hill, New York, USA, (1974), 134.

18) W. Kurz and D. J. Fisher: Fundamentals of Solidification, Trans. Tech. Publications, Aedermannsdorf, Switzerland, (1992), 63.

19) H. Esaka, K. Shinozuka and M. Tamura: ISIJ Int., 43 (2003), 1751.

20) H. Esaka, M. Shirakawa, K. Shinozuka and M. Tamura: ISIJ Int., 48 (2008), 264.

21) A. Suzuki, T. Suzuki, Y. Nagaoka and Y. Iwata: J. Jpn. Inst. Met., 32 (1968), 1301.

22) Handbook of Chemistry and Physics, ed. by D. R. Lide, CRC Press Inc., Boca Raton, Florida, USA, 78th ed., (1997), 12.

23) H. Mizuno, H. Esaka, K. Shinozuka and M. Tamura: ISIJ Int., 48 (2008), 277.

24) Z. Yamamoto: Steel Times, 217, April (1989), 180.

25) G. L. F. Powell and L. M. Hogan: J. Inst. Met., 93 (1964-1965), 505.

26) T. Kajitani, K. Okazawa, W. Yamada and H. Yamamura: ISIJ Int., 46 (2006), 1432.

27) M. C. Flemings: Solidification Processing, McGraw-Hill, New York, USA, (1974), 290.

28) M. Rappaz and Ch.-A. Gandin: Acta Metall. Mater., 41 (1993), 345.

29) Y. Natsume and K. Ohsasa: ISIJ Int., 46 (2006), 896.

30) Y. Kuroda, H. Esaka, K. Shinozuka and M. Tamura: CAMP-ISIJ, 18 (2005), 1016. 